pediatricians become familiar with a new piece of technology that may play a role in health care team protection and patient safety.

It is not possible to generalize this experience as a recommendation about the device use because its effectiveness in the pediatric clinical setting has not been demonstrated yet.

Further research to obtain evidence about these queries is still required.

\section{REFERENCES}

1. The Lancet. COVID-19: Protecting health-care workers. Lancet. 2020; 395(10228):922.

2. Tran K, Cimon K, Severn M, Pessoa-Silva CL, et al. Aerosol generating procedures and risk of transmission of acute respiratory infections to healthcare workers: a systematic review. PLoS One. 2012; 7(4):e35797.

3. Zuo MZ, Huang YG, Ma WH, Xue ZG, et al. Expert Recommendations for Tracheal Intubation in Critically ill Patients with Noval Coronavirus Disease 2019. Chin Med Sci J. 2020; 35(2):105-9.

4. Orser BA. Recommendations for Endotracheal Intubation of COVID-19 Patients. Anesth Analg. 2020; 130(5):1109-10.

5. Cook TM, El-Boghdadly K, McGuire B, McNarry AF, et al. Consensus guidelines for managing the airway in patients with COVID-19: Guidelines from the Difficult Airway Society, the Association of Anaesthetists the Intensive Care Society, the Faculty of Intensive Care Medicine and the Royal College of Anaesthetists. Anaesthesia. 2020; 75(6):785-99.

6. Matava CT, Kovatsis PG, Lee JK, Castro P, et al. Pediatric
Airway Management in COVID-19 Patients: Consensus Guidelines from the Society for Pediatric Anesthesia's Pediatric Difficult Intubation Collaborative and the Canadian Pediatric Anesthesia Society. Anesth Analg. 2020; 131(1):61-73.

7. Balaban O, Tobias JD. Videolaryngoscopy in Neonates, Infants, and Children. Pediatr Crit Care Med. 2017; 18(5): 477-85.

8. Grunwell JR, Kamat PP, Miksa M, Krishna A, et al. Trend and Outcomes of Video Laryngoscope Use Across PICUs. Pediatr Crit Care Med. 2017; 18(8):741-9.

9. Grünberg G. Intubación nasotraqueal con "videolaringoscopio artesanal" en paciente con vía aérea dificultosa prevista. Anest Analg Reanim. 2012; 25(2):55-60.

10. De Freitas J, Moreno J, Silva M. Prototipo de videolaringoscopio: Wi-Mac-Multivision. Rev Chil Anest 2020; 49(2):262-70.

11. Karippacheril JG, Umesh G, Ramkumar V. Inexpensive video-laryngoscopy guided intubation using a personal computer: Initial experience of a novel technique. J Clin Monit Comput. 2014; 28(3):261-4.

12. Simulación de Videolaringoscopía en lactante con COVID 19. [Accessed on: May 26 $6^{\text {th }}, 2020$ ]. Available at: https:// www.youtube.com/watch?v=7eAC6R17GuQ

13. Saito T, Taguchi A, Asai T. Videolaryngoscopy for tracheal intubation in patients with COVID-19. Br J Anaesth. 2020; 125(3):e284-6.

14. Hall D, Steel A, Heij R, Eley A, et al. Videolaryngoscopy increases 'mouth-to-mouth' distance compared with direct laryngoscopy. Anaesthesia. 2020; 75(6):822-3.

15. Begley JL, Lavery KE, Nickson CP, Brewster DJ. The aerosol box for intubation in coronavirus disease 2019 patients: an in-situ simulation crossover study. Anaesthesia. 2020; 75(8):1014-21.

\title{
Are electrocardiograms correctly interpreted by pediatric residents? Experience before and after an educational intervention in a teaching hospital
}

\author{
Georgina Bergero, M.D. ${ }^{a}$, Melina J. Saavedra, M.D. ${ }^{b}$, Marina Guglielmino, M.D. ${ }^{a}$, Amanda R. Soto Pérez, \\ M.D. ${ }^{a}$ Julián Llera, M.D. ${ }^{a}$ and Julio Busaniche, M.D. ${ }^{a}$
}

a. Division of Clinical Pediatrics, Department of Pediatrics.

b. Division of Pediatric Cardiology, Department of Pediatrics.

Hospital Italiano de Buenos Aires, Autonomous City of Buenos Aires. Argentina.

E-mail address:

Georgina Bergero, M.D.: bergerogeorgina@gmail.com

Funding: None.

Conflict of interest: None.

Received: $10-5-2020$

Accepted: $12-17-2020$

\begin{abstract}
The incidence of pediatric cardiac arrest is unknown; its main etiologies are congenital heart diseases, cardiomyopathies, and ventricular arrhythmias. An electrocardiogram (ECG) is a diagnostic method that may allow to detect them in an early manner and reduce morbidity and mortality.

The objective of this study was to describe pediatric residents' skills to determine if an ECG was normal or abnormal and make an accurate electrocardiographic diagnosis before and after an educational intervention. First-year pediatric residents participated in this study. An assessment including 12 ECG tracings was done before and after an educational module, and scores were compared using the t-test for paired data.

No differences were observed between both assessments regarding the interpretation of ECG as normal or abnormal ( $p: 0.42)$. However, a statistically significant difference was
\end{abstract}


observed in definitive diagnoses $(p<0.002)$. Definitive electrocardiographic diagnoses improved after the implementation of an educational module.

Key words: medical education, learning, cardiology, cardiac electrophysiology.

http: / / dx.doi.org/ 10.5546/aap.2021.eng.273

To cite: Bergero G, Saavedra MJ, Guglielmino M, Soto Pérez AR, et al. Are electrocardiograms correctly interpreted by pediatric residents? Experience before and after an educational intervention in a teaching hospital. Arch Argent Pediatr 2021;119(4):273-276.

\section{INTRODUCTION}

The electrocardiogram (ECG) is one of the most frequently used diagnostic methods because through cardiac electrical activity analysis, it is possible to detect multiple pathologies, including life-threatening ones. ${ }^{1}$ Pediatric cardiac arrest accounts for more than 2000 deaths each year in the United States. ${ }^{2}$ Its worldwide incidence is unknown. In contrast to adults, it is mainly the end result of progressive respiratory failure or shock. The most common etiologies of sudden cardiac arrest include congenital heart diseases, cardiomyopathies, and ventricular arrhythmias. ${ }^{3}$ In some cases, an early finding of electrocardiographic abnormalities may allow to establish a timely diagnosis and treatment, and thus reduce morbidity and mortality.

Recent studies have described that ECG interpretation is limited both among physicians and medical students. ${ }^{4-9}$ In addition; multiple residency programs do not offer formal ECG interpretation training. ${ }^{5}$

Pediatricians are often the first health care providers to assess children with a potential cardiac pathology. It is vital that these professionals are able to interpret ECGs. ${ }^{4}$

In Argentina, there are no publications addressing this problem. The objective of this study was to describe pediatric residents' skills to determine if an ECG was normal or abnormal and make an accurate diagnosis before and after an educational intervention.

\section{POPULATION AND METHODS}

This was a before-and-after, quasiexperimental study conducted between August and September 2019 at the Department of Pediatrics of a general teaching hospital with approximately 128000 pediatric visits every year.

Study participation was voluntary. First-year pediatric residents were invited to participate. Oral informed consent was obtained from those who agreed to do so.

Two tests were taken: pre-test and post-test. The educational module took place 30 days before the post-test. The tests included 12 ECG tracings chosen by a pediatric cardiologist, which were a representative sample of the pediatric practice due to their frequency of occurrence or severity. There were 4 normal or normal-variant ECG tracings and 8 abnormal ECG tracings (Table 1). ECGs were obtained at our institution and had 12 leads (see Annex).

Patients' name and age were removed. Tests were done in person and lasted 60 minutes. The ability to distinguish normal, normal-variant, and abnormal results by selecting these options was assessed, and an empty text box was provided to specify the diagnosis if they were able to identify it.

The educational module was given in person by a pediatric cardiologist, using slides and offering time to ask questions. It lasted 70 minutes and addressed electrode placement, the development of Bailey's hexaxial system and the analysis of heart rhythm, heart rate, atrioventricular conduction, wave characteristics, segments and intervals, electrical axis determination, and QTc. Normal and pathological ECGs were analyzed, which included the diagnoses used in the test, with different tracings.

Residents who did not complete both tests and those who did not attend the educational module were excluded. Correct results were not disclosed during the study. The protocol was approved by the hospital's Ethics Committee.

\section{Statistical analysis}

Two scores were determined: the first one considered if the ECG was identified as normal or abnormal, and the second one, if the diagnosis

TABLE 1. ECGs chosen for the tests

Normal ECGs

Normal ECG

Sinus tachycardia

Sinus bradycardia

Sinus arrhythmia

Abnormal ECGs

Left ventricular hypertrophy

Prolonged QTc interval

Wolff-Parkinson-White syndrome

Ventricular tachycardia

Complete right bundle branch block

Atrial flutter

Ventricular extrasystoles

Second-degree atrioventricular block 
indicated in the text box was correct or incorrect. The diagnosis was considered incorrect when the text box was left empty or incomplete. Both scores were expressed as percentage of correct answers per participant; the higher the percentage, the higher the number of correct answers.

Categorical outcome measures were described as absolute number and frequency, and continuous outcome measures as mean and standard deviation (SD) with a $95 \%$ confidence interval (CI) or median and interquartile range, based on the observed distribution. Scores were compared using the t-test for paired data. A value of $p<0.05$ was considered statistically significant. The STATA 13 software was used.

\section{RESULTS}

During the study period, there were 14 firstyear residents in the pediatric residency program, and they all agreed to participate. However, 2 of them were excluded for not attending the educational module or not taking the post-test. A total of 12 residents $(86 \%)$ were enrolled.

The correct interpretation of ECG tracings as normal or normal-variant and abnormal was analyzed, but no significant difference $(p=0.42)$ was observed between the $78.4 \%$ pre-test mean (SD: 13) and the $81.3 \%$ post-test mean (SD: 6.2). However, our study showed a statistically significant improvement in definitive diagnosis identification $(p<0.002)$ between the $22.2 \%$ pretest mean (SD: 14.8 ) and the $36.1 \%$ post-test mean (SD: 21.1) (Table 2).

\section{DISCUSSION}

Our study showed that implementing an educational module in a group of first-year pediatric residents aimed at analyzing and identifying pediatric ECGs significantly improved their ability to reach the correct diagnosis. In the bibliography, a recent meta-analysis concluded that ECG interpretation ability without any training was low and improved after educational interventions. In different populations, it was observed that, after training, improvement was less than expected. ${ }^{9}$

According to the study conducted by Khanna et al., a statistically significant difference was observed in the interpretation of the definitive diagnosis, with a $14 \%$ increase after the educational intervention. However, no differences were observed in our cohort regarding the ability to determine if an ECG was normal or abnormal. This finding may be due to the fact that, in our population, the percentage of correct answers in the pre-test $(78.4 \%)$ was considerably higher than in the above-mentioned study $(35.2 \%){ }^{2}$

Escudero et al. obteined similar results for the correct identification of the ECG as normal or abnormal, with a lower accuracy for the determination of the correct diagnosis. ${ }^{4}$ Regarding the identification of the definitive diagnosis, our population had lower scores than those previously published. ${ }^{6,7}$ This may be related to the fact that university training was based on interpreting adult ECGs.

TABLE 2. Percentage of residents' correct answers in the pre- and post-tests

\begin{tabular}{|c|c|c|c|c|}
\hline \multirow[b]{2}{*}{ First-year resident } & \multicolumn{2}{|c|}{ Normal/Abnormal } & \multicolumn{2}{|c|}{ Diagnosis } \\
\hline & Pre-test $(\%)$ & Post-test $(\%)$ & Pre-test $(\%)$ & Post-test $(\%)$ \\
\hline 1 & 66.6 & 83.3 & 33.3 & 50 \\
\hline 2 & 91.6 & 91.6 & 16.6 & 33.3 \\
\hline 3 & 91.6 & 91.6 & 33.3 & 25 \\
\hline 4 & 91.6 & 75 & 16.6 & 25 \\
\hline 5 & 58.3 & 75 & 25 & 50 \\
\hline 6 & 75 & 75 & 16.6 & 16.6 \\
\hline 7 & 66.6 & 83.3 & 8.3 & 8.3 \\
\hline 8 & 75 & 75 & 33.3 & 58.3 \\
\hline 9 & 75 & 75 & 16.6 & 16.6 \\
\hline 10 & 66.6 & 83.3 & 25 & 50 \\
\hline 11 & 100 & 83.3 & 50 & 75 \\
\hline 12 & 83.3 & 83.3 & 58.3 & 58.3 \\
\hline Mean (SD) & $78.4(13.0)$ & $81.2(6.2)$ & $22.2(14.8)$ & $36.1(21.1)$ \\
\hline$p$ value & \multirow{2}{*}{\multicolumn{2}{|c|}{$\begin{array}{c}0.42 \\
{[-4.7-10.4]}\end{array}$}} & \multirow{2}{*}{\multicolumn{2}{|c|}{$\begin{array}{c}0.002 \\
{[5.9-21.8]}\end{array}$}} \\
\hline $95 \% \mathrm{CI}$ & & & & \\
\hline
\end{tabular}

SD: standard deviation; CI: confidence interval. 
The greatest difficulty faced by our population was to identify diagnoses as prolonged QT interval, Wolff-Parkinson-White syndrome, atrioventricular block, and complete right bundle branch block, which was consistent with published studies. ${ }^{2,4,6}$ However, in our population, most participants were able to identify abnormal ECGs, which in clinical practice would have resulted in the corresponding referral to more experienced physicians.

In the study by Crocetti et al., the strongest predictor of ECG interpreting was completing a cardiology rotation. ${ }^{8}$ Our residency program currently lacks a formal cardiology rotation.

Although ECG interpreting is a complex task even for cardiologists, it is extremely important that pediatric residents interpret them correctly and identify conditions requiring medical action or referral to a specialist. Based on this study, the annual implementation of an ECG educational module in our residency program and followup during the subsequent years to assess the progression in the acquisition of these skills are considered relevant.

\section{Limitations}

This study was conducted in a single center and its sample size was small. It included firstyear pediatric residents, which could result in a selection bias.

Regarding its methodology, patients' age was removed from the ECGs in order to protect their privacy, which hindered a correct interpretation. In addition, it was necessary to clarify that, if several anomalies were found, the most significant one should be noted, given that, for instance, in the ECG with second-degree atrioventricular block, some residents answered "incomplete right bundle branch block," which was not the main anomaly. Finally, the post-test was done 30 days after the intervention; therefore, the ability to retain the information in the long term was not assessed.

\section{CONCLUSION}

Our cohort of residents showed a good performance when determining if an ECG was normal or abnormal. The identification of the definitive diagnosis improved after an educational module. Nevertheless, it is necessary to include more training opportunities in order to attain better levels of diagnostic accuracy.

\section{REFERENCES}

1. Rolskov Bojsen S, Räder SBEW, Holst AG, Kayser L, et al. The acquisition and retention of ECG interpretation skills after a standardized web-based ECG tutorial-a randomized study. BMC Med Educ. 2015; 15:36.

2. Khanna S, Iyer VR, Vetter VL. Can Pediatric Practitioners Correctly Interpret Electrocardiograms? J Pediatr. 2019; 206:113-8.

3. Sherwin ED, Berul CI. Sudden Cardiac Death in Children and Adolescents. Card Electrophysiol Clin. 2017; 9(4):569-79.

4. Escudero CA, Sanatani S, Wong KK, Templeton CG. Electrocardiogram interpretation by Canadian general paediatricians: Examining practice, accuracy and confidence. Paediatr Child Health. 2014; 19(2):77-83.

5. JheetaJS, Narayan O, Krasemann T. Accuracy in interpreting the paediatric ECG: UK-wide study and the need for improvement. Arch Dis Child. 2014; 99(7):646-8.

6. Snyder CS, Bricker JT, Fenrich AL, Friedman RA, et al. Can pediatric residents interpret electrocardiograms? Pediatr Cardiol. 2005; 26(4):396-9.

7. De Jager J, Wallis L, Maritz D. ECG interpretation skills of South African emergency medicine residents. Int J Emerg Med. 2010; 3(4):309-14.

8. Crocetti M, Thompson R. Electrocardiogram interpretation skills in pediatric residents. Ann Pediatr Cardiol. 2010; 3(1):3-7.

9. Cook DA, Oh SY, Pusic MV. Accuracy of Physicians' Electrocardiogram Interpretations: A Systematic Review and Meta-analysis. JAMA Intern Med. 2020; 180(11):1-11. 


\section{ANNEX. \\ ELECTROCARDIOGRAMS CHOSEN FOR THE TESTS}

1) Normal ECG tracing

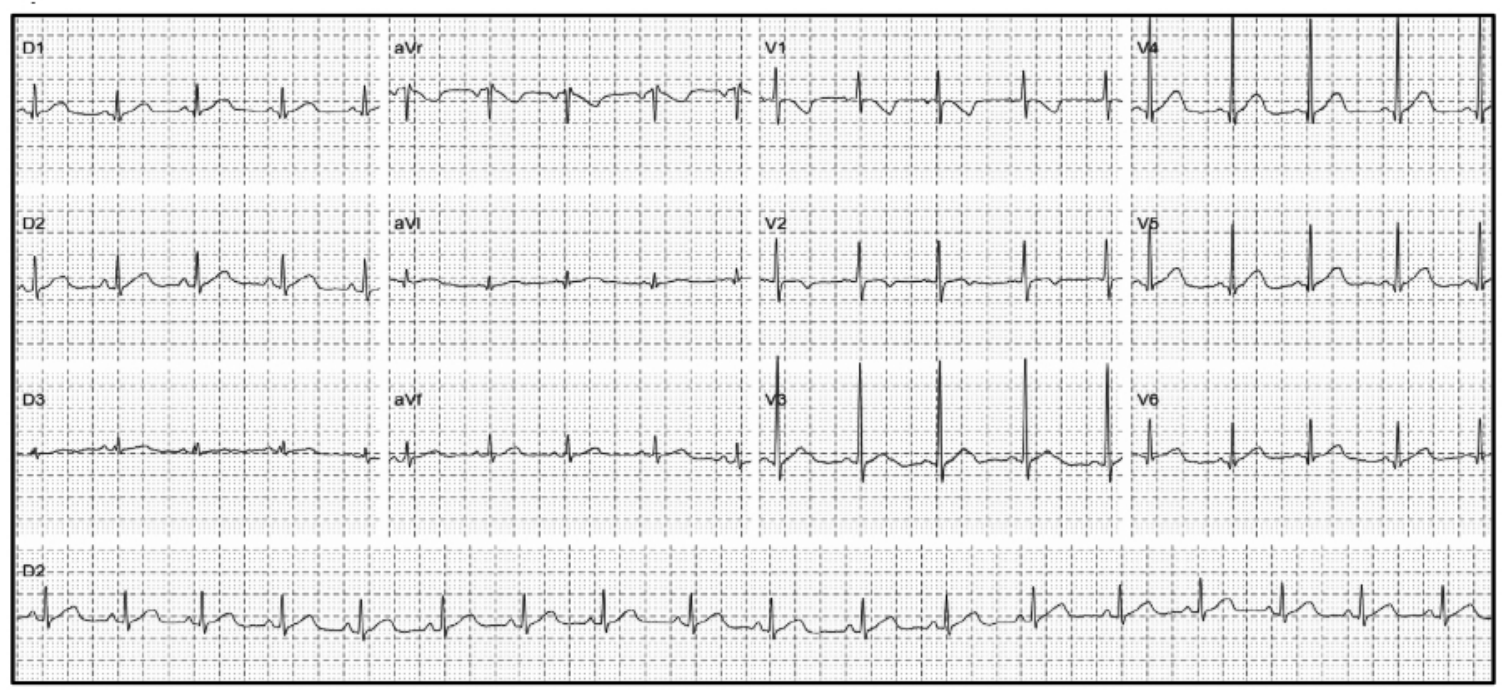

2) Left ventricular hypertrophy

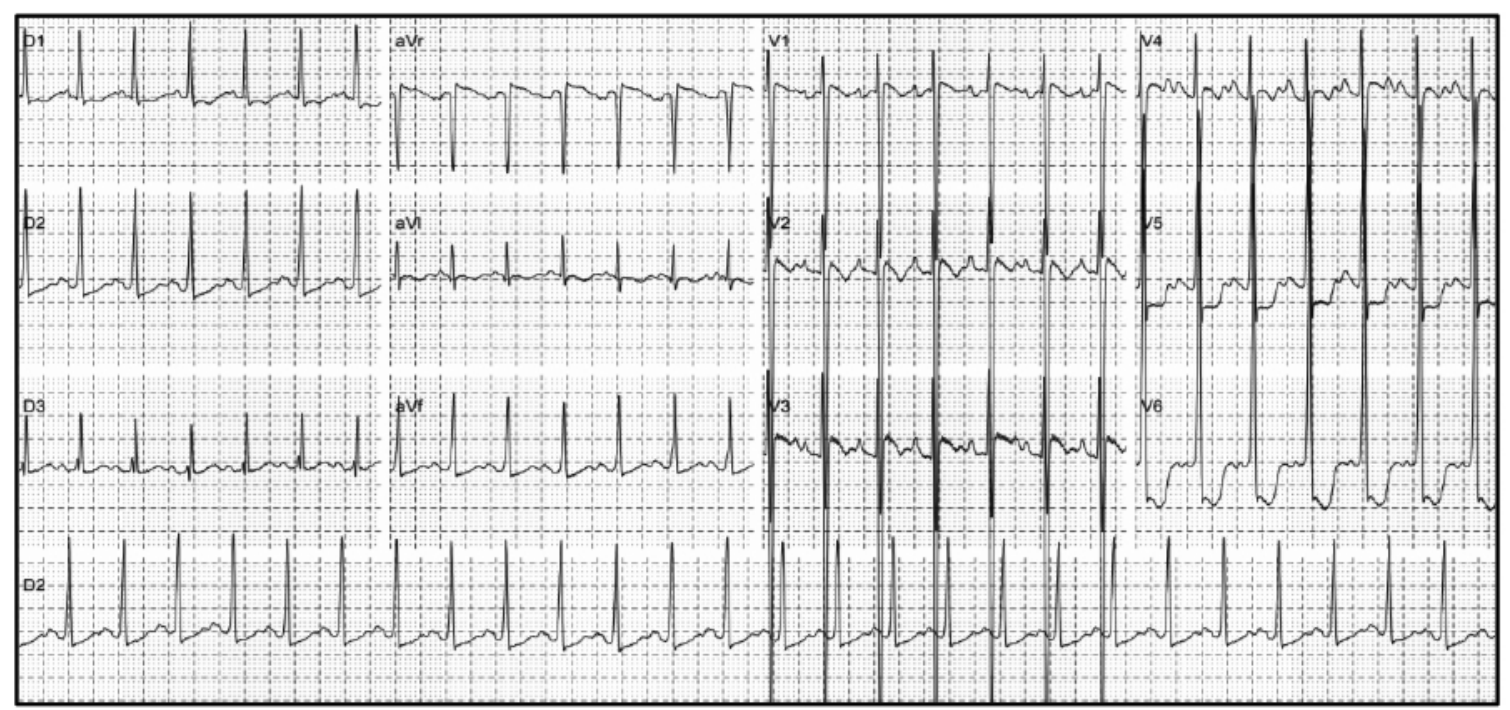




\section{3) Sinus tachycardia}

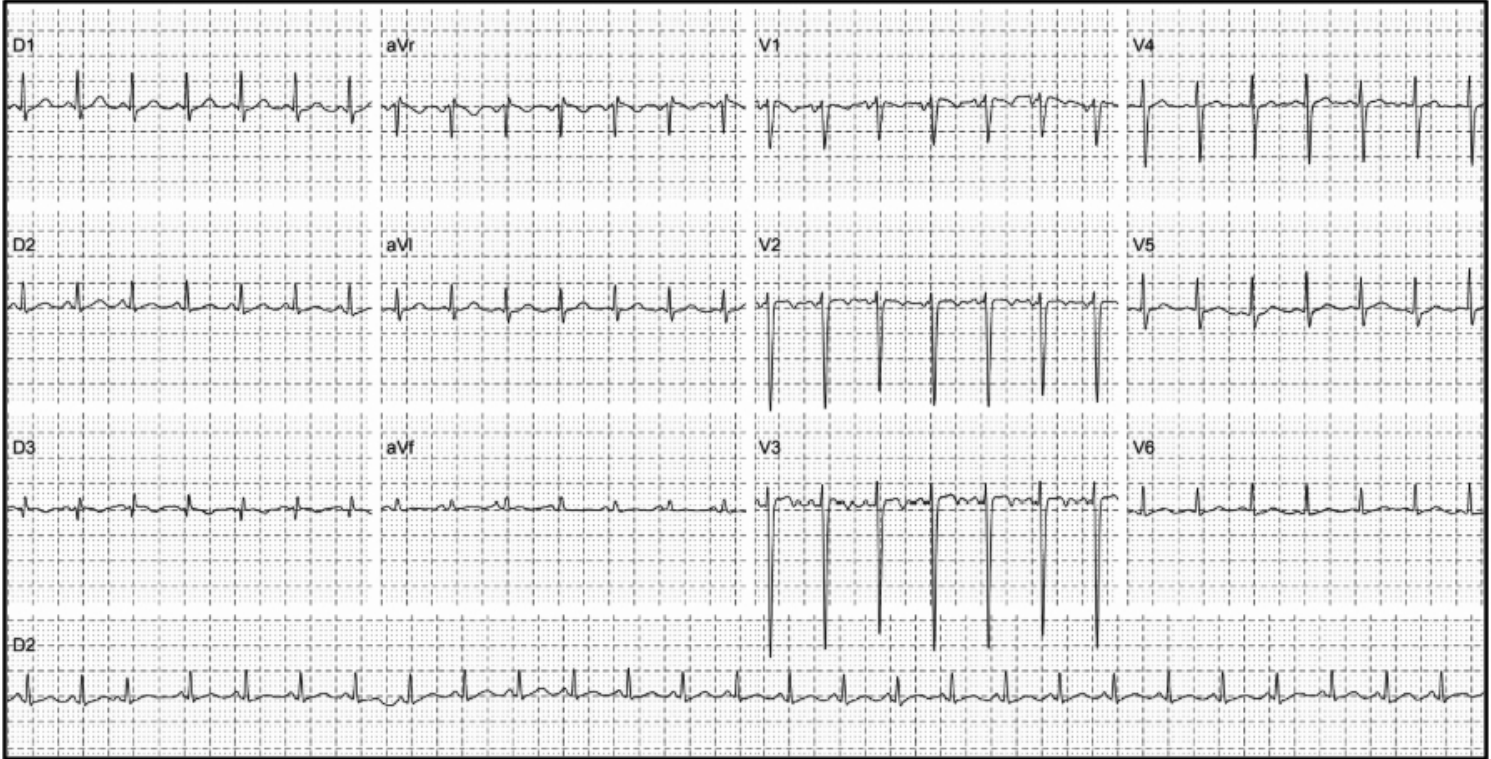

\section{4) Prolonged QTc interval}

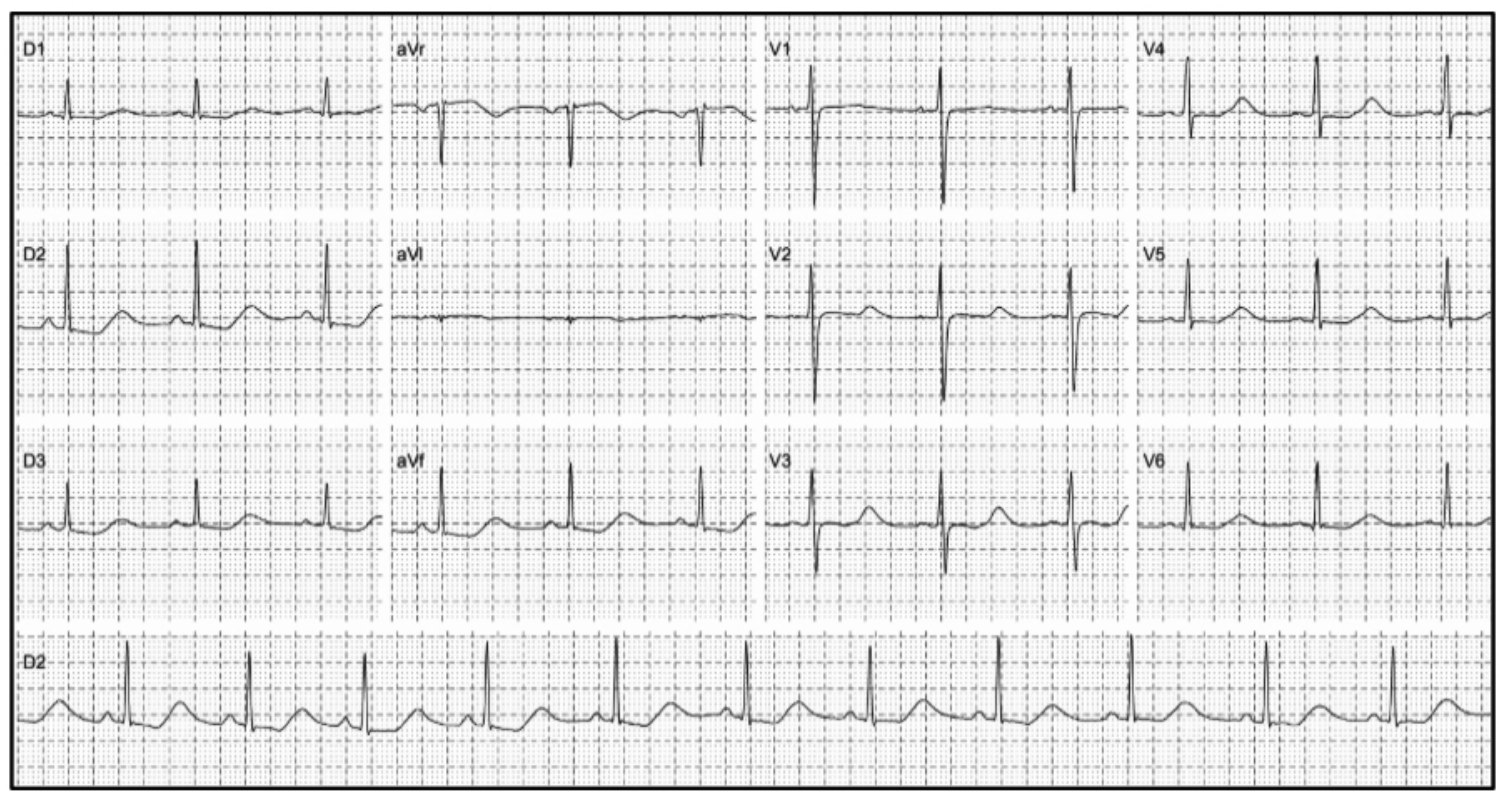


5) Wolff-Parkinson-White syndrome

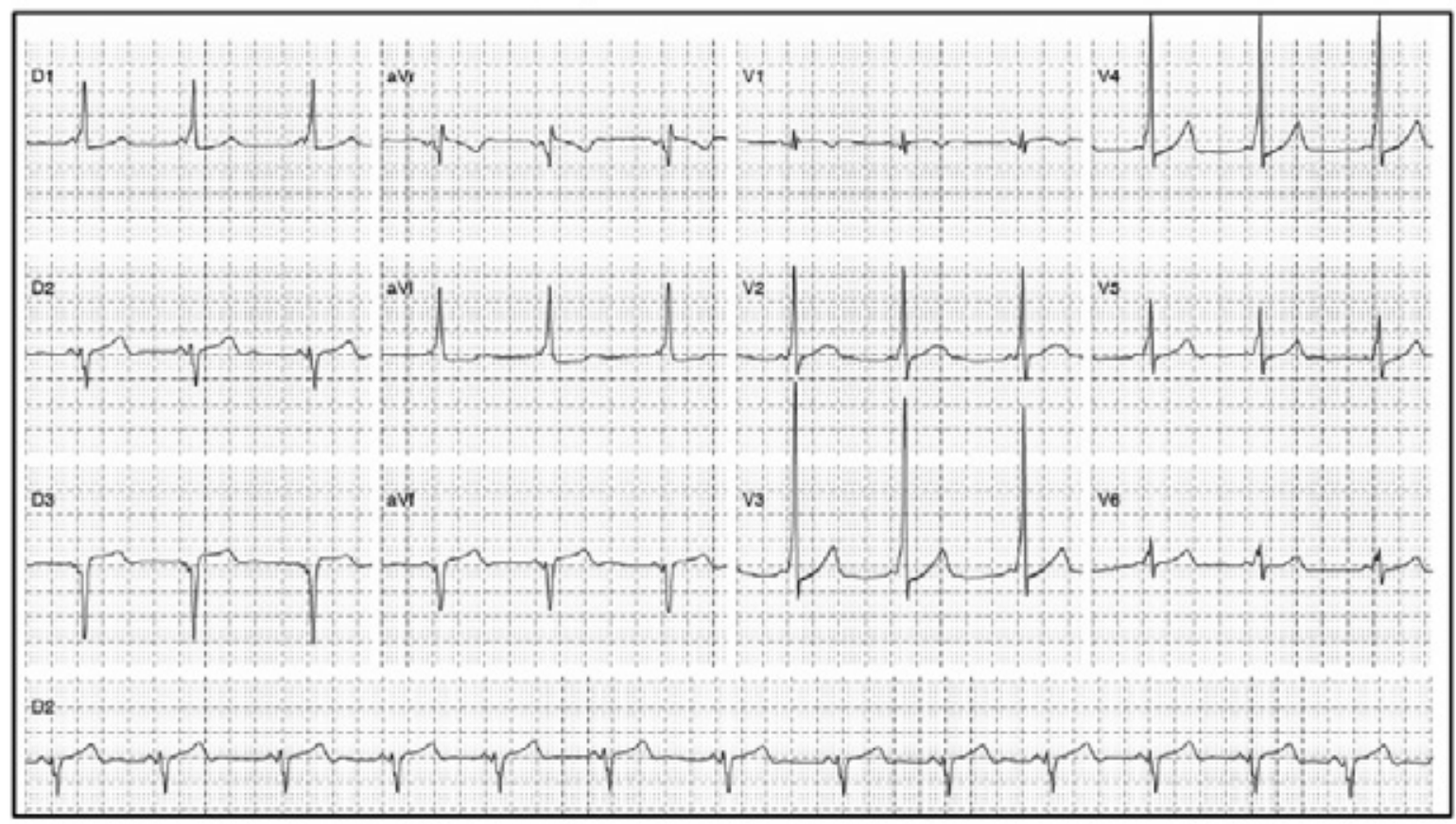

6) Ventricular tachycardia

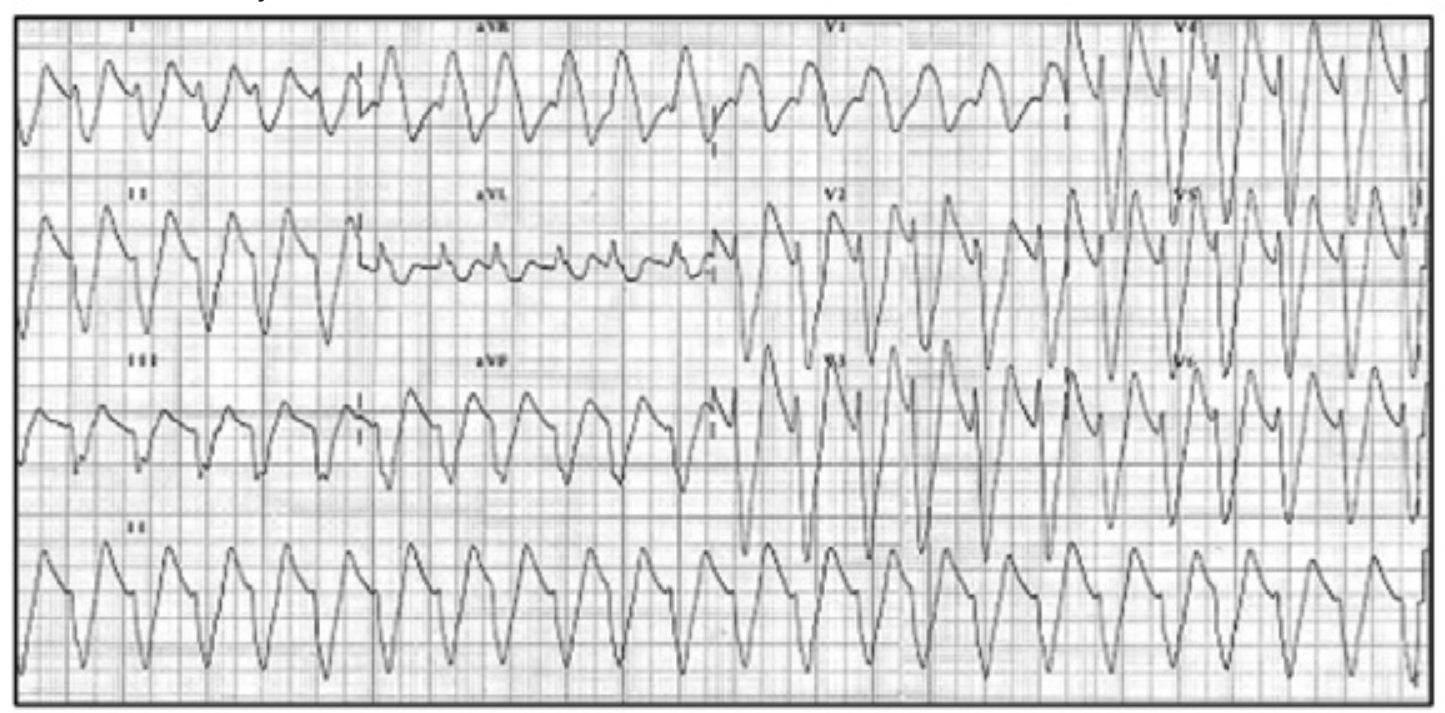


7) Sinus bradycardia

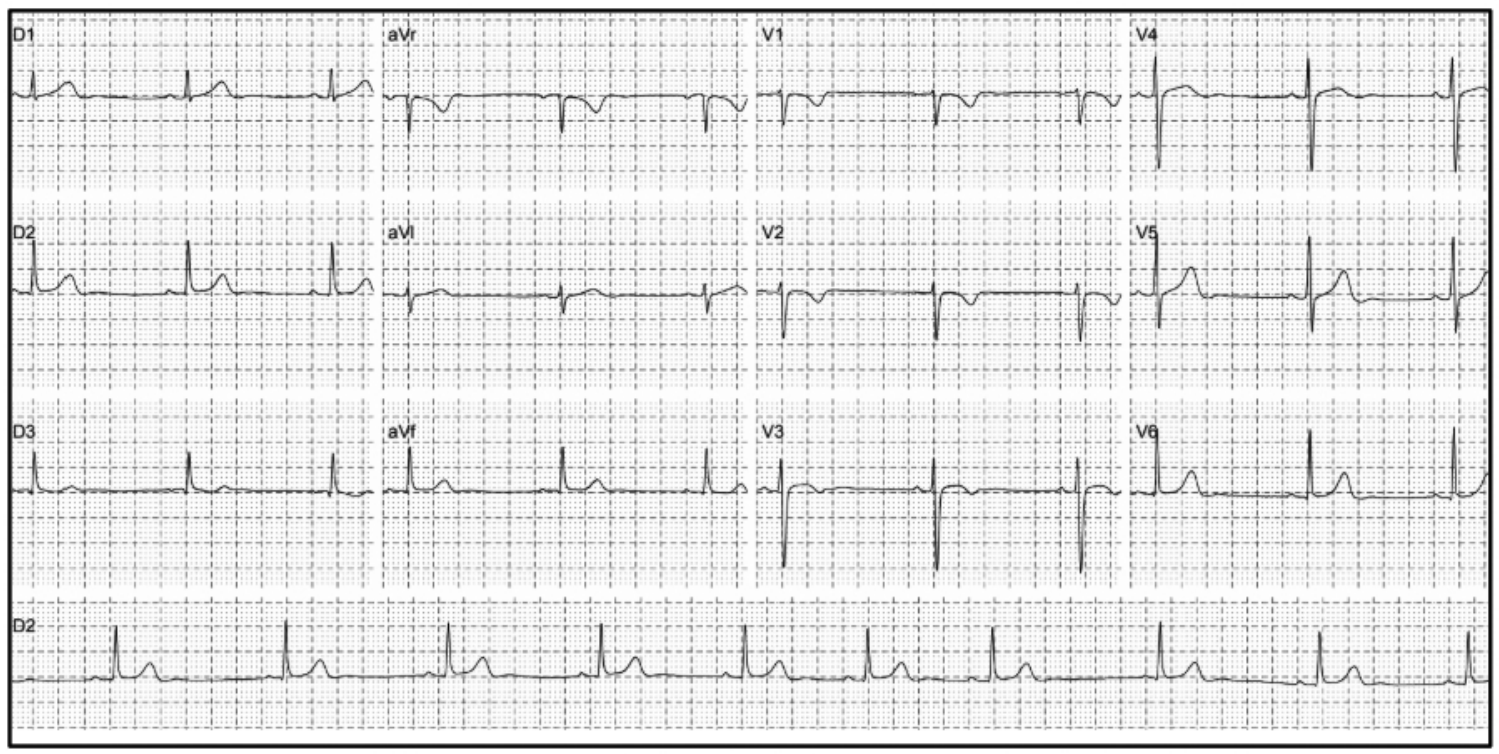

8) Complete right bundle branch block

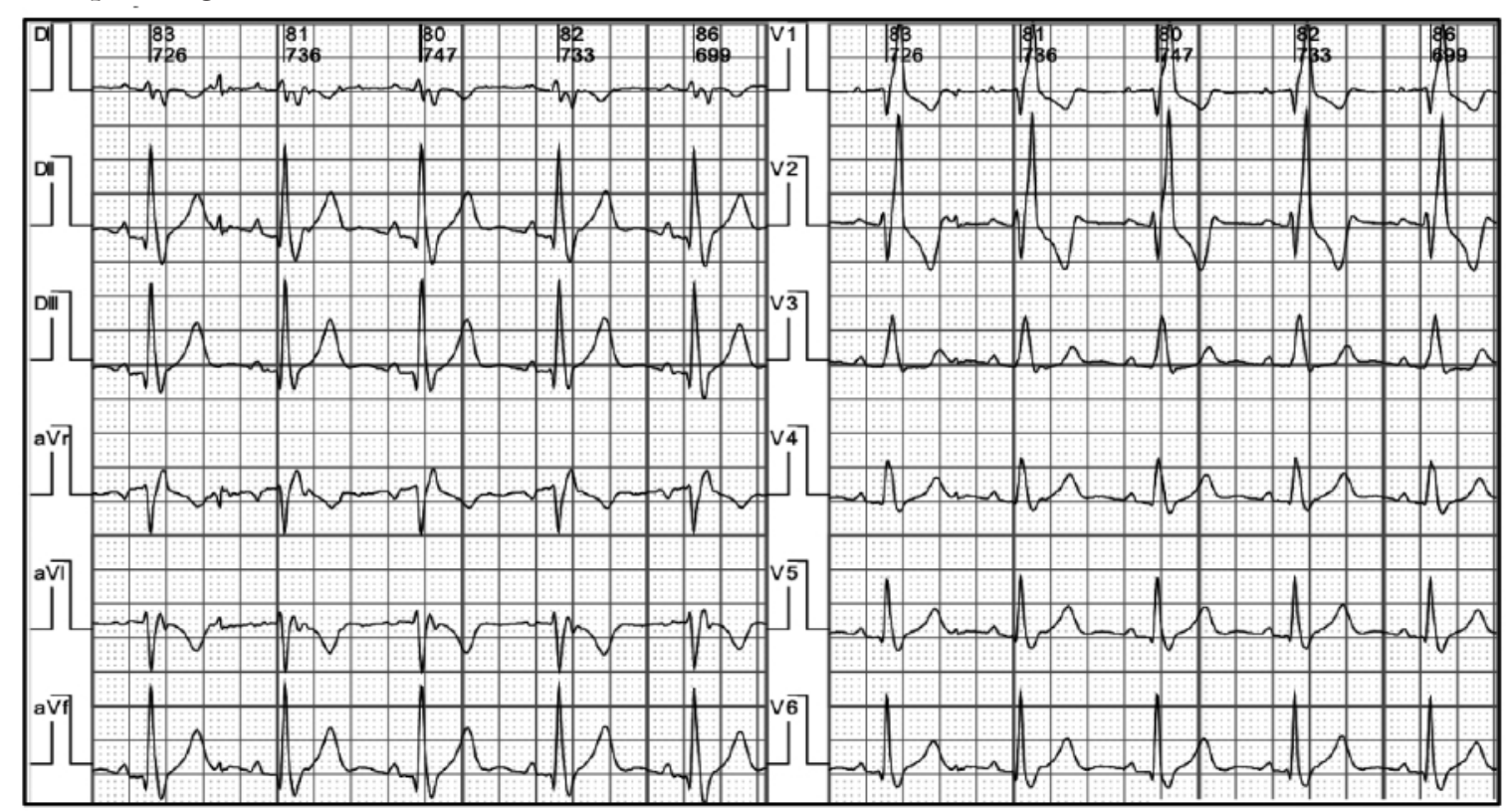


9) Atrial flutter

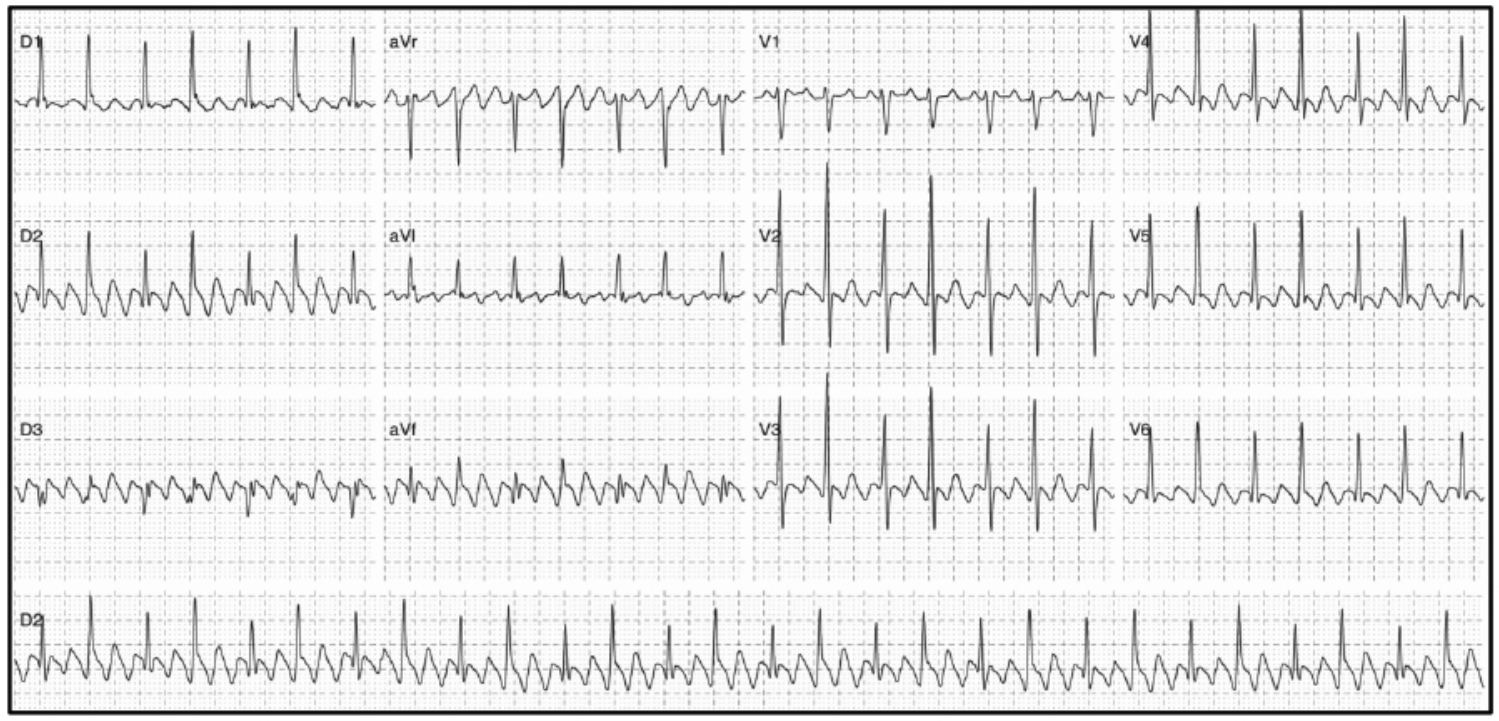

10) Respiratory sinus arrhythmia

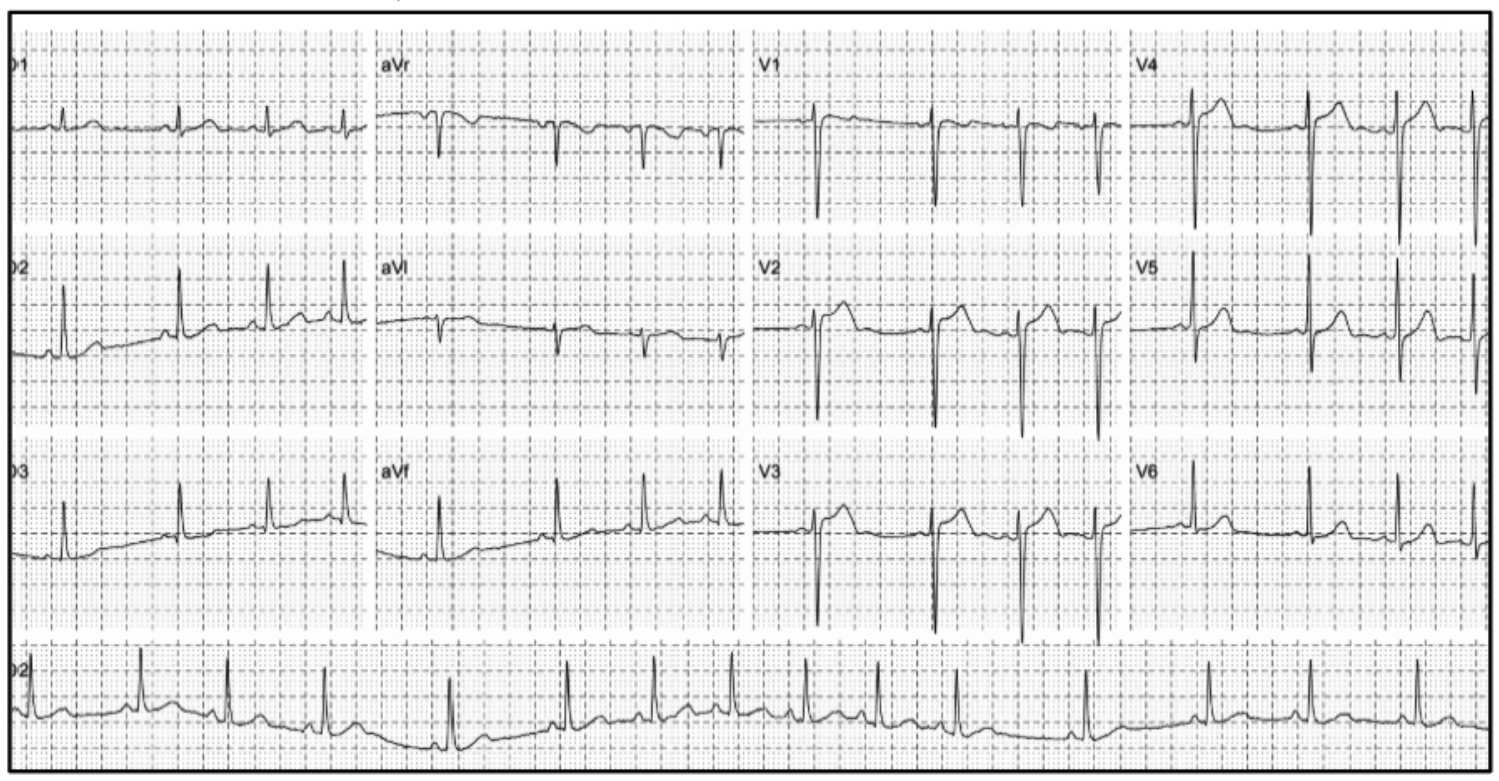


11) Ventricular extrasystoles

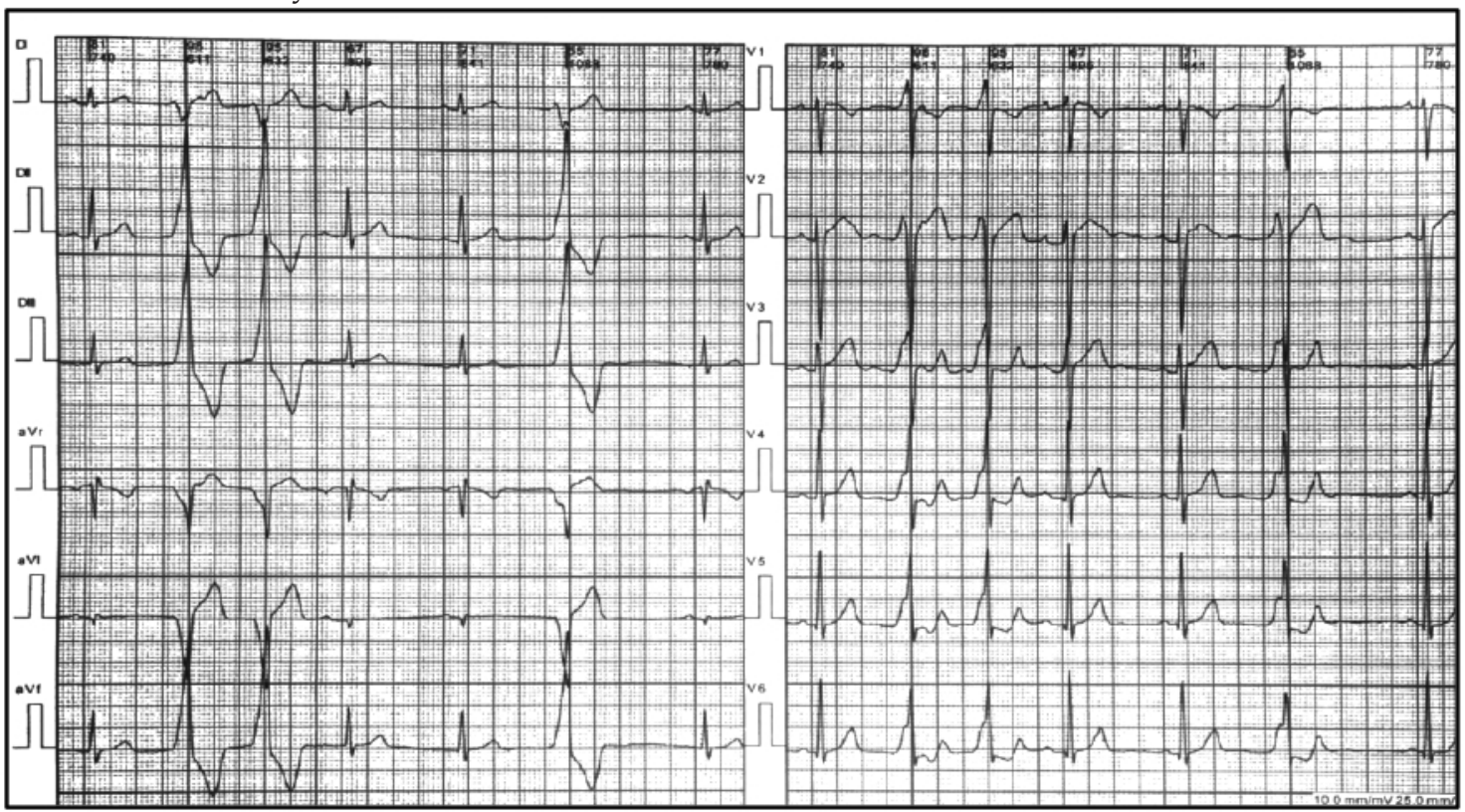

12) Second-degree atrioventricular block, Mobitz type 1

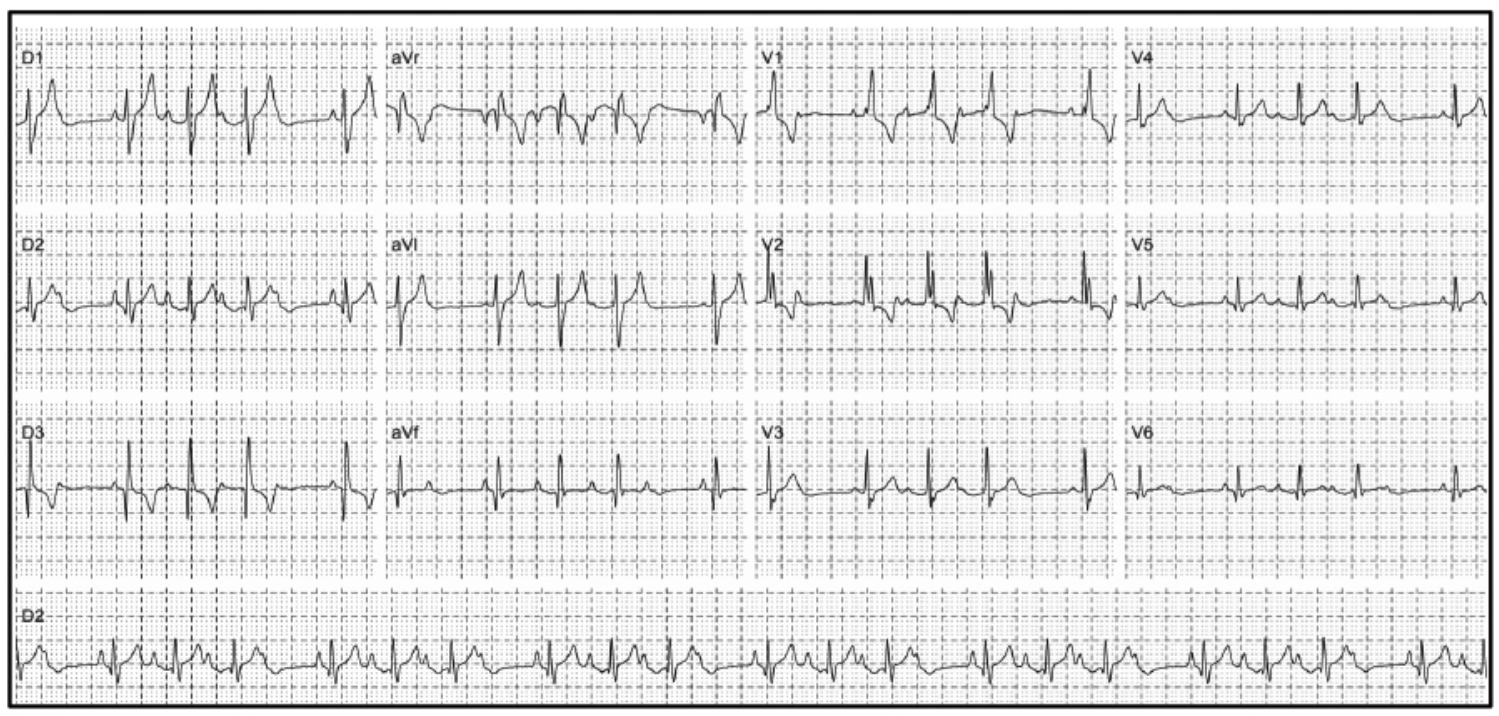

